\title{
PARAQUAT POISONING: A CASE REPORT
}

\section{M. Kabade ${ }^{1}$, Anand Koppad ${ }^{2}$, Ameet V. Khatawakar ${ }^{3}$, P. B. Vijaylaxmi ${ }^{4}$, Gavisiddanagowda Patil ${ }^{5}$}

\section{HOW TO CITE THIS ARTICLE:}

D. M. Kabade, Anand Koppad, Ameet V. Khatawakar, P. B. Vijaylaxmi, Gavisiddanagowda Patil. "Paraquat Poisoning: A Case Report". Journal of Evolution of Medical and Dental Sciences 2015; Vol. 4, Issue 35, April 30; Page: 6143-6147, DOI: $10.14260 /$ jemds/2015/894

\begin{abstract}
Paraquat $\{\mathrm{PQ}\}$, a herbicide available as $20 \%$ solution can cause lethal effects due to production of free radicals formed by the cyclic oxidation-reduction reactions of the compound with tissues resulting in multiorgan failure. Symptoms of PQ ingestion are usually dose-dependent, and intoxication can be categorized to mild, moderate, and fulminant. Most common symptoms being vomiting (100\%) followed by oral ulceration (59\%), dysphagia (53\%) and dyspnea (41\%). Diagnosis of PQ poisoning is usually made based on circumstantial evidences. PQ levels can be estimated and is of prognostic significance. Almost always PQ causes morbidty and mortality except in few cases where dose is inadequate. Here we present a case of 25 year old patient with PQ poisoning which resulted in oral mucosal and upper gastrointestinal ulcerations which subsequently healed with antioxidants, antibiotics and local applications of povidine iodine. As there were no respiratory symptoms cyclophosphamide or steroids was not used. Patient was discharged after 1 month of hospital admission with all parameters within normal limits. . In spite of advances in medical care, prompt treatment, and supportive care, mortality still remains high mainly due to multiorgan failure.
\end{abstract}

KEYWORDS: Paraquat, Poisoning, Haemoperfusion.

INTRODUCTION: Paraquat $\{\mathrm{PQ}\},(1,1$ ' -dimethyl-4, 4'- bipyridium dichloride) a brown or bright green corrosive liquid is most common suicidal poisoning responsible for high morbidity and mortality, available in a $20 \%$ solution form. First synthesized in 1882, is being used as a herbicide since $1955 .{ }^{1}$ Lethal dose is $30 \mathrm{mg} / \mathrm{kg}$, equivalent to $8-10 \mathrm{ml}$ of the $20 \%$ solution sold commercially.2,3 Its toxic effects originate from the production of free radicals formed by the cyclic oxidationreduction reactions of the compound in tissues, main acute systemic effects being pulmonary oedema, convulsions, cardiac, renal, and hepatic failure. Despite studies and clinical practice in the last few decades, little improvement has been made in reducing the fatality of $P Q$ poisoning, but there is a comparatively high mortality. Although widely available, incidence and reports of PQ poisoning are not common in India. We discuss a case of suicide in which an unknown amount of PQ was consumed and presented with mild-moderate form of toxicity.

CASE: A 25-year-old male, admitted with an alleged history of attempted suicidal consumption of PQ, unknown quantity, at his residence. Initially managed locally with (intravenous fluids emetics and $\mathrm{H}_{2}$ blockers), brought to our hospital for further treatment, after 6 hours of consumption. He presented with h/o difficulty in swallowing, nausea and vomiting with negative history for loose stools, abdominal pain, breathlessness, cough, seizures, or fever.

On clinical examination, patient was conscious, oriented, pupils bilaterally equally reactive, afebrile, pulse rate of 80 beats per min regular, blood pressure was $110 / 70 \mathrm{~mm}$. $\mathrm{Hg}$, respiratory rate of 16 per min with $98 \% \mathrm{spo}_{2}$. Systemic examination was unremarkable. Gastric lavage with activated 
charcoal was performed in the emergency department. Patient had mild anaemia (Hb was 9.9gm \%). Other blood investigations were within normal limits.

\begin{tabular}{|c|c|c|}
\hline Investigations & On admission & After 1 week \\
\hline Heamoglobin & $9.9 \mathrm{mg} / \mathrm{dl}$ & $10.8 \mathrm{mg} / \mathrm{dl}$ \\
\hline RBC & $4.2 \mathrm{million} / \mathrm{cumm}$ & $4.7 \mathrm{million} / \mathrm{cumm}$ \\
\hline PCV & $33.1 \%$ & $36 \%$ \\
\hline MCV & $78.4 \mathrm{cum}$ & $76.6 \mathrm{cum}$ \\
\hline MCH & $23.5 \mathrm{mmg}$ & $23 \mathrm{mmg}$ \\
\hline MCHC & $29.9 \%$ & $30 \%$ \\
\hline WBC & 8,500 cells/cumm & $6,900 \mathrm{cells} / \mathrm{cumm}$ \\
\hline Platelet & $2.91 \mathrm{lakhs} / \mathrm{cumm}$ & $4.1 \mathrm{lakhs} / \mathrm{cumm}$ \\
\hline RDW & $13.7 \%$ & $13.6 \%$ \\
\hline Glucose & $105 \mathrm{mg} / \mathrm{dl}$ & $89 \mathrm{mg} / \mathrm{dl}$ \\
\hline Urea & $68 \mathrm{mg} / \mathrm{dl}$ & $24 \mathrm{mg} / \mathrm{dl}$ \\
\hline Creatinine & $1.3 \mathrm{mg} / \mathrm{dl}$ & $1.2 \mathrm{mg} / \mathrm{dl}$ \\
\hline Sodium & $132 \mathrm{~m} . \mathrm{mol} / \mathrm{l}$ & $129 \mathrm{~m} . \mathrm{mol} / \mathrm{l}$ \\
\hline Potassium & $4.7 \mathrm{~m} . \mathrm{mol} / \mathrm{l}$ & $3.6 \mathrm{~m} . \mathrm{mol} / \mathrm{l}$ \\
\hline Total protein & $7.1 \mathrm{~g} / \mathrm{dl}$ & $7 \mathrm{~g} / \mathrm{dl}$ \\
\hline Albumin & $3.5 \mathrm{~g} / \mathrm{dl}$ & $3.1 \mathrm{~g} / \mathrm{dl}$ \\
\hline Bilirubin total & $0.5 \mathrm{mg} / \mathrm{dl}$ & $0.6 \mathrm{mg} / \mathrm{dl}$ \\
\hline Bilirubin - Direct & $0.2 \mathrm{mg} / \mathrm{dl}$ & $0.3 \mathrm{mg} / \mathrm{dl}$ \\
\hline AST & $18 \mathrm{U} / \mathrm{L}$ & $20 \mathrm{U} / \mathrm{L}$ \\
\hline ALT & $32 \mathrm{U} / \mathrm{L}$ & $36 \mathrm{U} / \mathrm{L}$ \\
\hline ALP & $45 \mathrm{U} / \mathrm{L}$ & $42 \mathrm{U} / \mathrm{L}$ \\
\hline HIV, HBs.Ag & Nonreactive & Nonreactive \\
\hline ECG, 2D-ECHO & No abnormality detected & No abnormality detected \\
\hline Chest x ray & No abnormality detected & No abnormality detected \\
\hline
\end{tabular}

Table 1: Table of investigations, on admission and after one week

His chest x-ray was normal on day 1 on day 6 and day 15. Upper gastrointestinal endoscopy showed small petechial haemorrhage in the body, lesser curvature and antrum of stomach. Features of duodenitis were present. Oesophagus, vocal cords, pyriform fossa was normal. He received inj. piperacillin-tazobactum $4.5 \mathrm{~g}$ i. $\mathrm{v}$ tid, oral vitamin c $(500 \mathrm{mg}$ ) qid, vitamin E (400 mg), $\mathrm{N}$-acetyl cysteine, antiemetics, antacid syrup, and local applications of lignocaine, metrogyl, povidine iodine mouth wash.

DISCUSSION: Symptoms of PQ ingestion are usually dose-dependent, and intoxication can be categorized to mild, moderate, and fulminant. $P Q \leq 20 \mathrm{mg} / \mathrm{kg}$ causing mild intoxication, usually present with minor gastrointestinal problems like transient vomiting, diarrhea, and oropharyngeal burns. Usually complete recovery is possible. Doses between $>20 \mathrm{mg} / \mathrm{kg}$ and $<50 \mathrm{mg} / \mathrm{kg}$ cause moderate intoxication. While $\geq 50 \mathrm{mg} / \mathrm{kg}$ of the poison have a fulminant course, causing multi organ 
failure, may lead to death within 3 days.3,4,5 Sandhu et al., 2003 mentioned frequency of common symptoms for PQ poisoning as vomiting (100\%) followed by oral ulceration (59\%), dysphagia (53\%) and dyspnea (41\%). ${ }^{6}$ Gastrointestinal toxicity is universal in those ingesting PQ concentrate. Mucosal lesions of the mouth and the tongue ('Paraquat tongue'), 7 that appear within the first few days and may become ulcerated with bleeding are of little prognostic significance as they occur even in those who spit PQ out without swallowing (the products commonly contain stenching and bittering agents). Mucosal lesions in the pharynx, oesophagus and stomach are also very common and much more sinister. These may result in perforation, mediastinitis and/or pneumomediastinum. In patients who survive longer, fibrotic changes in the alveoli result in gas exchange interference in the lungs and may progress to ARDS. Renal tubular necrosis and hepatic necrosis may occur. It has been found that plasma concentration of $>1.6 \mathrm{pg} / \mathrm{ml} 12 \mathrm{~h}$ after ingestion is universally fatal.8 Diagnosis of PQ poisoning is usually made based on circumstantial evidences. It is always important to identify ingested amount of substance as specifically as possible, unfortunately unavailable in our patient. In our patient, the clinical history, presentation, and documentation of PQ consumption endorses the diagnosis positive as urinary and serum levels could not be estimated because of lack of laboratories performing PQ levels.

In spite of advances in medical care, prompt treatment, and supportive care, mortality still remains high, in such patients, mainly due to multiorgan failure. High dose ingestion or severe PQ poisoning has a poor prognosis. Conventional treatment includes nasogastric tube fixation, gastric lavage with normal saline, charcoal-sorbitol or fuller's earth lavage, forced alkalinized diuresis and hemodialysis or hemoperfusion. In contrast, the use of oxygen can enhance the toxicity by providing more electron acceptors. If at all needed, oxygen should be given in lower concentrations to the hypoxic patients.

Hemoperfusion with activated charcoal is effective if initiated within 4 hours of PQ intoxication. As our patient was admitted 6 hours after consumption, hemoperfusion was not performed. As seen in the present case, PQ ingestion resulted in an inflammation of the tongue, oral mucosa and throat, corrosive injury to the gastrointestinal tract. The patient complained of burning and ulceration of the throat, tongue and esophagus initially but after a week all symptoms resolved except for oral ulcerations. At present, there is no specific antidote to PQ poisoning. Therefore, it is recommended that the crucial focus should be on preventive measures. In case of oral exposure, aggressive decontamination should be instituted to prevent further absorption.

CONCLUSION: The available data suggest rare incidence, high mortality \& Morbidity, and very few survivors, following PQ poisoning. We report our experience of acute PQ poisoning with oral, mucosal and upper GI ulceration. The unexplained combination of gastrointestinal symptoms, acute renal injury, and respiratory failure must lead to suspicion of PQ toxicity, even in the absence of ingestion history. If patient presents early, the therapeutic interventions with hemo perfusion and dialysis may be recommended to prevent pulmonary and multi-organ failure. Both, urine and serum concentrations of samples at known time intervals, post-ingestion, are to be determined, not only for assessing severity of the intoxication, but also to predict and improve the survival chances.

ACKNOWLEDGMENT: We express our gratitude to Departments of Pathology, Biochemistry, Microbiology, ENT, Surgery and Psychiatry of KIMS hospital, Hubli, for their valuable inputs and support, and also to our patient and their relatives for their co-operation. 


\section{CASE REPORT}

\section{REFERENCES:}

1. Yang CJ, Lin JL, Lin-Tan DT, Weng CH, et al: Spectrum of toxic hepatitis following intentional paraquat ingestion: analysis of 187 cases. Liver Int 32: 1400-1406, 2012.

2. Yoon SC: Clinical outcome of paraquat poisoning. Korean J Intern Med 24: 93-94, 2009.

3. Kavitha Saravu, Sonal Sekhar, Ananth Pai, Ananthakrishna Shastry Barkur, et al: Paraquat - A deadly poison: Report of a case and review. Indian J Crit Care Med. 2013 May-Jun; 17 (3): 182184.

4. Dinis-Oliveira RJ, Duarte JA, Sánchez-Navarro A, Remião F, Bastos ML, Carvalho F. Paraquat poisonings: Mechanisms of lung toxicity, clinical features, and treatment. Crit Rev Toxicol. 2008; 38: 13-71.

5. Dinis-Oliveira RJ, Sarmento A, Reis P, Amaro A, Remiao F, Bastos ML, et al. acute paraquat poisoning: Report of a survival case following intake of a potential lethal dose. Pediatr Emerg Care. 2006; 22: 537-40.

6. Sandhu JS, Dhiman A, Mahajan R, Sandhu P. Outcome of paraquat poisoning- a five year study. Indian J Nephrol. 2003; 13: 64-8.

7. Balasubramanian Madhan, Gnanasekaran Arunprasad, Balasubramanian Krishnan: Paraquat tongue BMJ Case Rep 2014.

8. Sittipunt C. Paraquat poisoning. Respir Care. 2005; 50: 383-5.

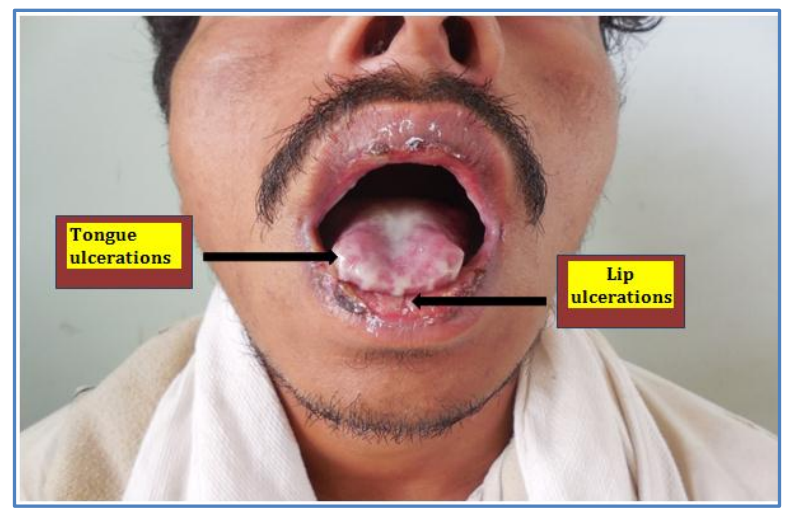

\section{Fig. 1: Ulcerations over tongue and lips due to paraquat}

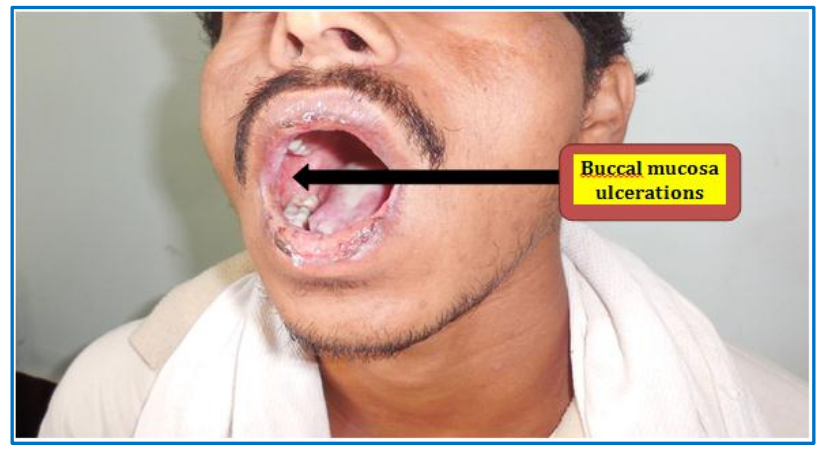

Fig. 2: Ulcerations of buccal mucosa due to paraquat poisoning 


\section{AUTHORS:}

1. D. M. Kabade

2. Anand Koppad

3. Ameet V. Khatawakar

4. P. B. Vijaylaxmi

5. Gavisiddanagowda Patil

\section{PARTICULARS OF CONTRIBUTORS:}

1. Associate Professor, Department of General Medicine, KIMS, Hubli.

2. Assistant Professor, Department of General Medicine, KIMS, Hubli.

3. Assistant Professor, Department of General Medicine, KIMS, Hubli.

4. Professor \& HOD, Department of General Medicine, KIMS, Hubli.

FINANCIAL OR OTHER

COMPETING INTERESTS: None
5. Senior Resident, Department of General Medicine, KIMS, Hubli.

\section{NAME ADDRESS EMAIL ID OF THE CORRESPONDING AUTHOR:}

Dr. D. M. Kabade,

"SRUJAN" House No. 64,

Akshaya Colony Phase I,

Near Akshaya Colony Circle,

Chetna College Road,

Hubli-580030, Karnataka.

E-mail: sampradakabade@gmail.com

Date of Submission: 08/04/2015.

Date of Peer Review: 09/04/2015.

Date of Acceptance: 22/04/2015.

Date of Publishing: 30/04/2015. 